\title{
Sistem Informasi Manajemen Gudang Pada PT. Datindo Infonet Prima Bekasi
}

\author{
Frasdica Fujianto Nugraha ${ }^{1 *}$, Nunu Kustian, M.Kom ${ }^{1}$, dan Risma Nurul Auliya, S.Si,. M.Pd ${ }^{3}$ \\ ${ }^{123}$ Universitas Indraprasta PGRI \\ Jl. Raya Tengah No.80, RT.6/RW.1, Kel. Gedong, Kec. Pasar Rebo \\ Kota Jakarta Timur, Daerah Istimewa Jakarta 13760 \\ frasdica1@gmail.com, kustiannunu@gmail.com, rismauliya@gmail.com
}

\begin{abstract}
Abstrak - PT. Datindo Infonet Prima Bekasi merupakan perusahaan penyediaan barang dan jasa dalam bidang perbankan. Dalam membantu mengatasi permasalahan yang berkaitan tentang pengelolaan data manajemen gudang di PT. Datindo Infonet Prima Bekasi yang belum terkomputerisasi. Metode yang digunakan oleh penulis merupakan metode deskriptif yang bertujuan untuk menyajikan gambaran mengenai situasi yang terjadi di perusahaan dan studi kasus dengan model pembuatan sistem menggunakan metode Research and Development (R\&D) agar dapat memberikan pemahaman mengenai situasi yang terjadi di perusahaan. Berdasarkan hasil pengujian sistem diperoleh bahwa rancangan sistem informasi ini dapat memberikan kemudahan pada karyawan dalam mengelola manajemen gudang pada PT. Datindo Infonet Prima Bekasi Bekasi, sehingga proses pengelolaan menjadi lebih tepat dan efisien.
\end{abstract}

Kata kunci: Sistem, Manajemen

Abstract - PT. Datindo Infonet Prima Bekasi is a company providing goods and services in the banking sector. In helping to overcome problems related to the management of warehouse management data at PT. Datindo Infonet Prima Bekasi which is not yet computerized. The method used by the author is a descriptive method that aims to present an overview of the situation that occurs in the company and a case study with a system creation method using the Research and Development $(R \& D)$ model which aims to provide understanding of the situation that occurs in the company. Based on the results of system testing, it is found that the design of this information system can provide convenience to employees in managing warehouse management at PT. Datindo Infonet Prima Bekasi Bekasi, so that the management process becomes more precise and efficient.

Keywords: System, Management

\section{Pendahuluan}

Manajemen pergudangan memiliki peran penting di perusahaan. Secara umum, kegiatan yang dilakukan oleh manajemen gudang, yaitu meliputi penerimaan, penempatan, penyimpanan sementara, pemindahan, pemeriksaan, hingga pengiriman barang ke lokasi tujuan konsumen.

Pada pelaksanaannya, sistem pergudangan yang berjalan masih dilakukan dengan catatan pembukuan oleh administrasi gudang. Kemudian, data tersebut digunakan dalam pembuatan laporan distribusi yang dilaporkan pada pemimpin perusahaan setiap bulannya. Keseluruhan proses manajemen di gudang masih dilakukan secara konvensional sehingga rentan terhadap terjadinya kesalahan yang diakibatkan oleh kelalaian manusia. Oleh sebab itu maka gudang membutuhkan sistem yang terkomputerisasi agar dapat menggantikan proses konvensional, sehingga kinerja karyawan di perusahaan dapat lebih efektif dan efisien, serta mengurangi dampak kelalaian manusia dalam proses laporan data manajemen gudang kepada pemimpin perusahaan yang dilakukan setiap bulannya.

Solusi yang dapat mengatasi masalah yang dipaparkan dengan merancang suatu sistem informasi mengenai manajemen pergudangan, yang dituangkan dalam penelitian yang berjudul "SISTEM INFORMASI MANAJEMEN GUDANG PADA PT. DATINDO INFONET PRIMA BEKASI". Sistem informasi ini diharapkan dapat mempermudah kinerja karyawan untuk menentukan dan membuat laporan barang perbankan yang terdapat di gudang secara cepat dan akurat. Dengan demikian, solusi ini akan berdampak pada kinerja perusahaan dalam memenuhi target yang telah ditentukan.

\section{Tinjauan Pustaka}

\subsection{Konsep Dasar Sistem}

Sistem adalah rangkaian tersusun dari beberapa materi yang saling berhubungan dan berinteraksi.[1]. Sistem mempunyai organisasi, hubungan yang saling menguntungkan dan mempunyai tujuan[2]. Kesimpulan bahwa sistem adalah rangkaian yang berhubungan dan saling bergantung agar bisa meraih target yang telah di tetapkan. 


\subsection{Dasar Sistem Informasi}

Sistem informasi adalah sesuatu yang terdapat pada organisasi dan mempertemukan kebutuhan pengolahan transaksi serta mendukung kegiatan manajerial.[3]. Sistem informasi adalah mengumpulkan, menganalisa dan membagikan informasi untuk tujuan tertentu[4]. Kesimpulan sistem informasi adalah suatu pengolahan transaksi dengan mengumpulkan dan menganalisis.

2.3. Pengerian Sistem Informasi Manajemen

Sistem informasi manajemen merupakan bagian dari pengendalian internal suatu bisnis, meliputi: pemanfaatan sumber daya manusia, teknologi, dokumen dan prosedur manajemen untuk memecahkan masalah bisnis. [5]. Sistem Informasi Manajemen (SIM) adalah sebuah sistem informasi yang melakukan semua pengolahan transaksi yang diperlukan oleh organisasi, Semua perkembangan baru dapat dirasakan manfaatnya jika dukungan sumber daya manusianya kompeten[6]. Dengan demikian, dapat kesimpulan bahwa suatu sistem yang dirancang untuk menyediakan informasi guna mendukung pengambilan keputusan pada kegiatan manajemen organisasi.

\subsection{Pengerian Gudang}

Gudang ialah tempat untuk penyimpanan barang sementara waktu. Pengertian gudang yakni suatu kegiatan yang berkaitan dengan tempat penyimpanan barang sementara[7].

2.5. Pengertian Diagram Alir Data (DAD)

Diagram Alir Data (DAD) diartikan sebagai sebuah alat bergambar atau diagram dalam membangun sebuah sistem perancangan, bertujuan untuk menjelaskan alur dan konsep pada sistem yang dibangun, hingga memudahkan para pengembang dan pengguna dalam memahami konsep sistem tersebut [8][15].

\subsection{Entity Relationship Diagram (ERD)}

Entity Relationship Diagram (ERD) ialah model yang dirangkai berdasarkan tujuan[9]. ERD merupakan alat bantu dalam model database yang berguna untuk menjelaskan menghubungan antar tabel[10].

2.7. Kamus Data

Kamus data dirangkai berdasarkan arus yang ada pada Alir Data (DAD).[11]. Kamus data dirangkai pada tahap perancangan sistem[12].

\subsection{Normalisasi}

Mendefinisikan normalisasi sebagai proses pengolahan file untuk menghilangkan kelompok yang berangkaian[13].

\section{Metode Penelitian}

Desain penelitian adalah keseluruhan proses yang dibuat dalam merancang dan dilaksanakannya penelitian[14].

1. Metode observasi (Pengamatan langsung)

Observasi dilakukan secara langsung dengan mengunjungi gudang PT. Datindo Infonet Prima Bekasi untuk mengamati permasalahan yang terjadi dan merancang sistem yang akan dibutuhkan. Data yang diperoleh yaitu sistem yang masih berjalan secara konvensional.

2. Metode interview (Wawancara)

Interview dilakukan agar mengetahui masalah yang terkait dengan gudang PT. Datindo Infonet Prima Bekasi. Berdasarkan hasil yang di dapat dari interview, peneliti mengumpulkan data mengenai masalah yang dialami oleh karyawan, sejarah singkat, struktur organisasi, proses bisnis dan tanggung jawab struktur yang ada di PT. Datindo Infonet Prima Bekasi

3. Metode Studi Kepustakaan (Literature)

Peneliti melakukan studi kepustakaan dari berbagai sumber, seperti dari buku-buku, artikel atau jurnal yang ditujukan untuk dipelajari dan memahami dasar teori yang berhubungan dengan sistem manajemen. 


\section{Hasil dan Pembahasan}
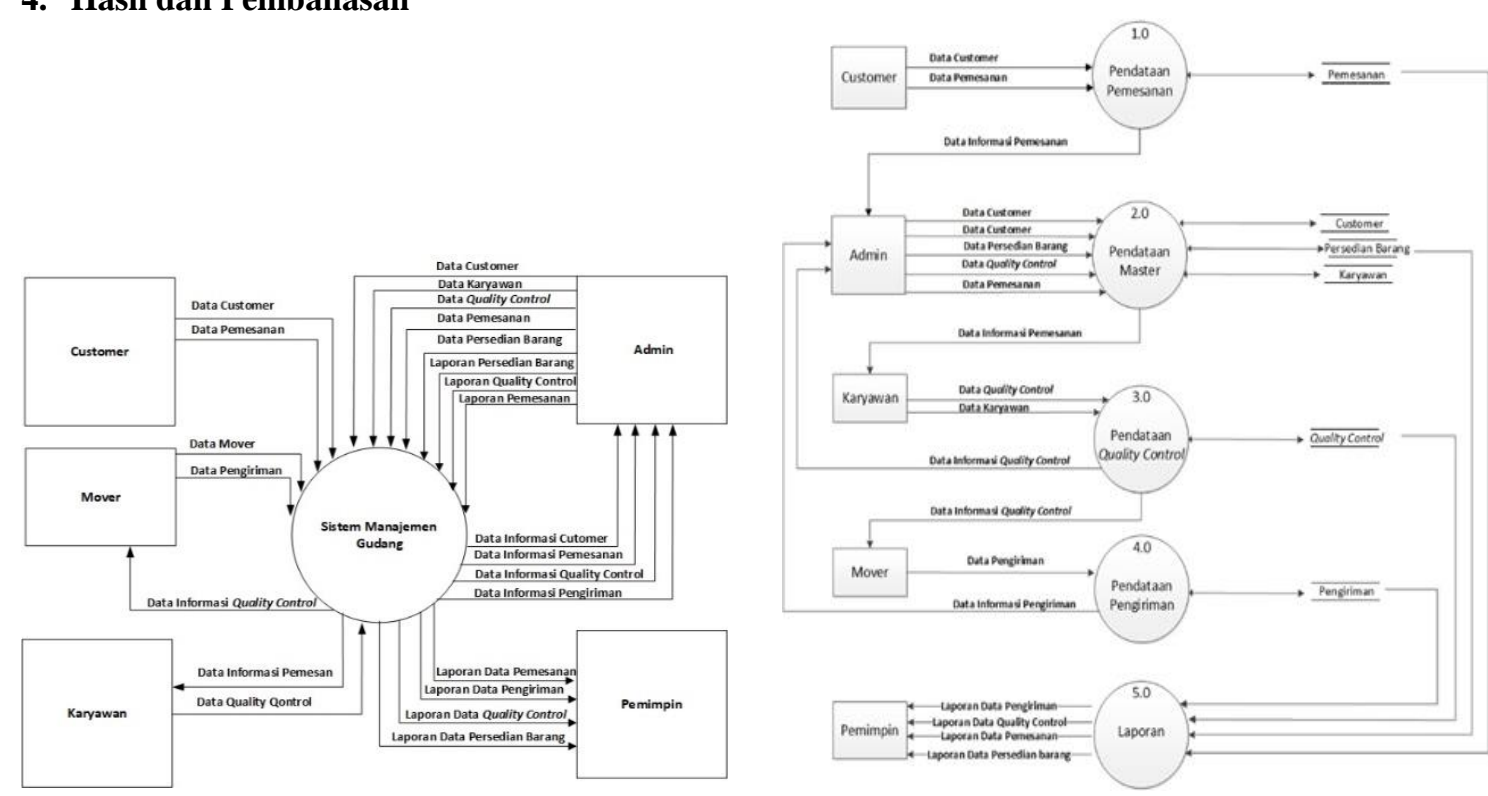

Gambar 1. Diagram Konteks Diusulkan

Gambar 2. Diagram Nol Sistem yang Diusulkan

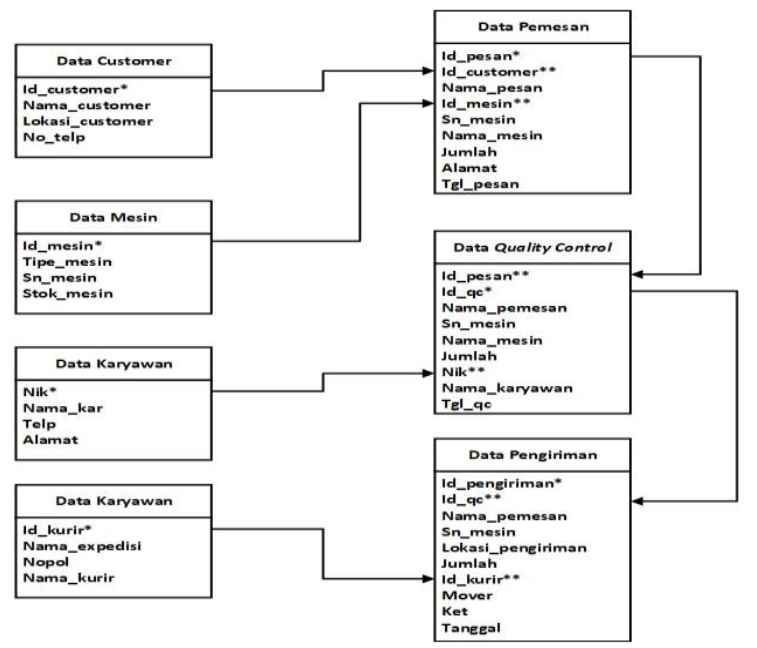

Gambar 3. Normalisasi

1. Spesifikasi File

Nama Tabel

Media

Data Customer

Primary Key

Panjang Record

: Hardisk

: id_customer

$: 375$

Jumlah Record

$: 375000$

Tabel 1 Data Customer

\begin{tabular}{cccc}
\hline Kolom & Jenis & Atribut & Kosong \\
\hline Id_id_customer* $^{*}$ & Varchar & 20 & Tidak \\
Nama_customer & Varchar & 30 & Tidak \\
Lokasi_customer & Varchar & 20 & Tidak \\
No_telp & Varchar & 20 & Tidak \\
\hline
\end{tabular}



2. Nama Tabel : : Data Barang
Media : Hardisk
Primary Key : : id_barang
Panjang Record : : 740
Jumlah Record $\quad$ : 740000

Tabel 2 Data Barang

\begin{tabular}{cccc}
\hline Kolom & Jenis & Atribut & Kosong \\
\hline Id_barang* & Varchar & 20 & Tidak \\
Sn_barang & Varchar & 30 & Tidak \\
Tipe_barang & Varchar & 250 & Tidak \\
Stok_barang & Varchar & 20 & Tidak \\
\hline
\end{tabular}

$\begin{array}{ll}\text { 3. Nama Tabel } & : \text { Data Pemesan } \\ \text { Media } & : \text { Hardisk } \\ \text { Primary Key } & : \text { id_pesan } \\ \text { Foreign Key } & : \text { id_customer, id_barang } \\ \text { Panjang Record } & : 220 \\ \text { Jumlah Record } & : 220000\end{array}$

Tabel 3 Data Pemesan

\begin{tabular}{cccc}
\hline Kolom & Jenis & Atribut & Kosong \\
\hline Id_pesan* & Varchar & 20 & Tidak \\
Id_customer** & Varchar & 50 & Tidak \\
Nama_pesan & Varchar & 50 & Tidak \\
Id_barang** & Varchar & 20 & Tidak \\
Sn_barang & Varchar & 50 & Tidak \\
tipe_barang & Varchar & 10 & Tidak \\
Jumlah & Varchar & 10 & Tidak \\
Alamat & Varchar & 20 & Tidak \\
Tgl_pesan & Date & - & Tidak \\
\hline
\end{tabular}

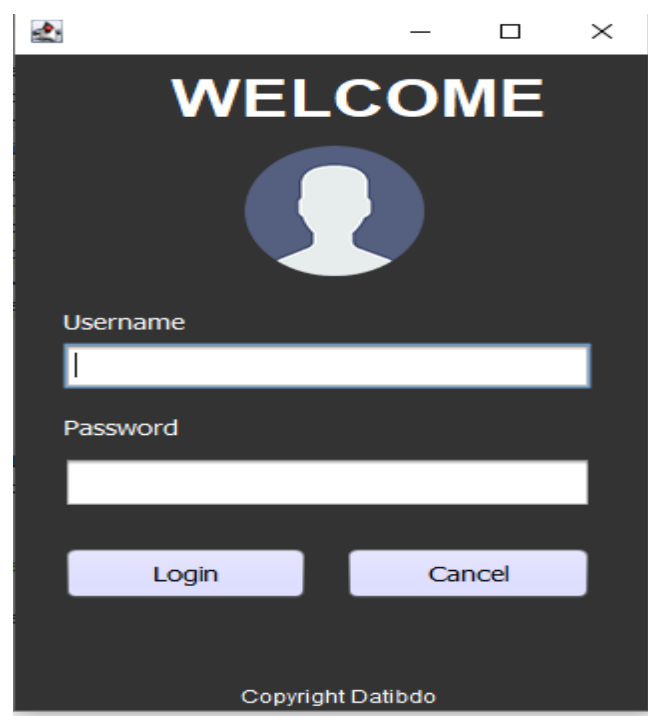

Gambar 4. Menu Login 


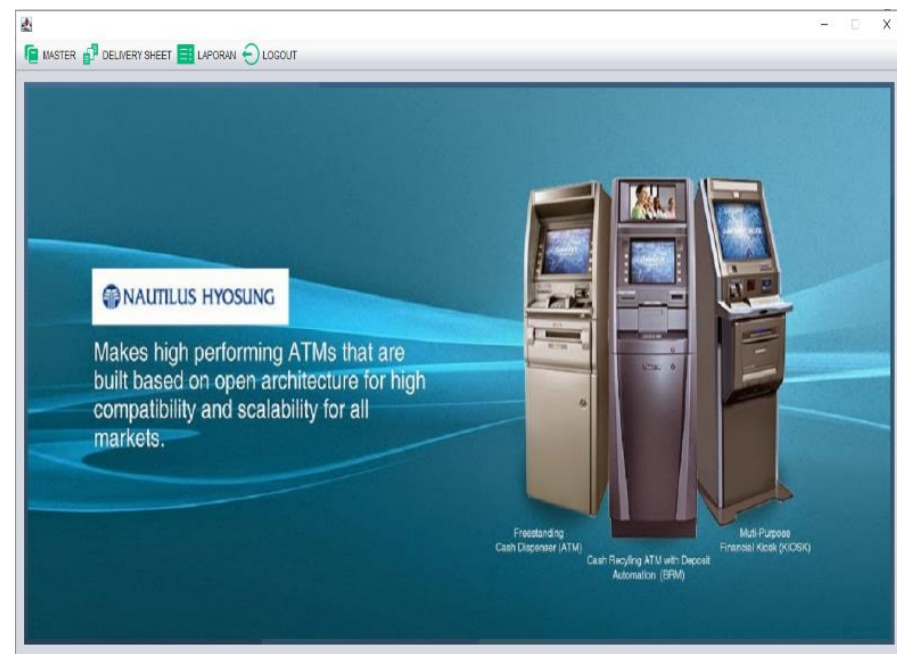

Gambar 5. Menu Home
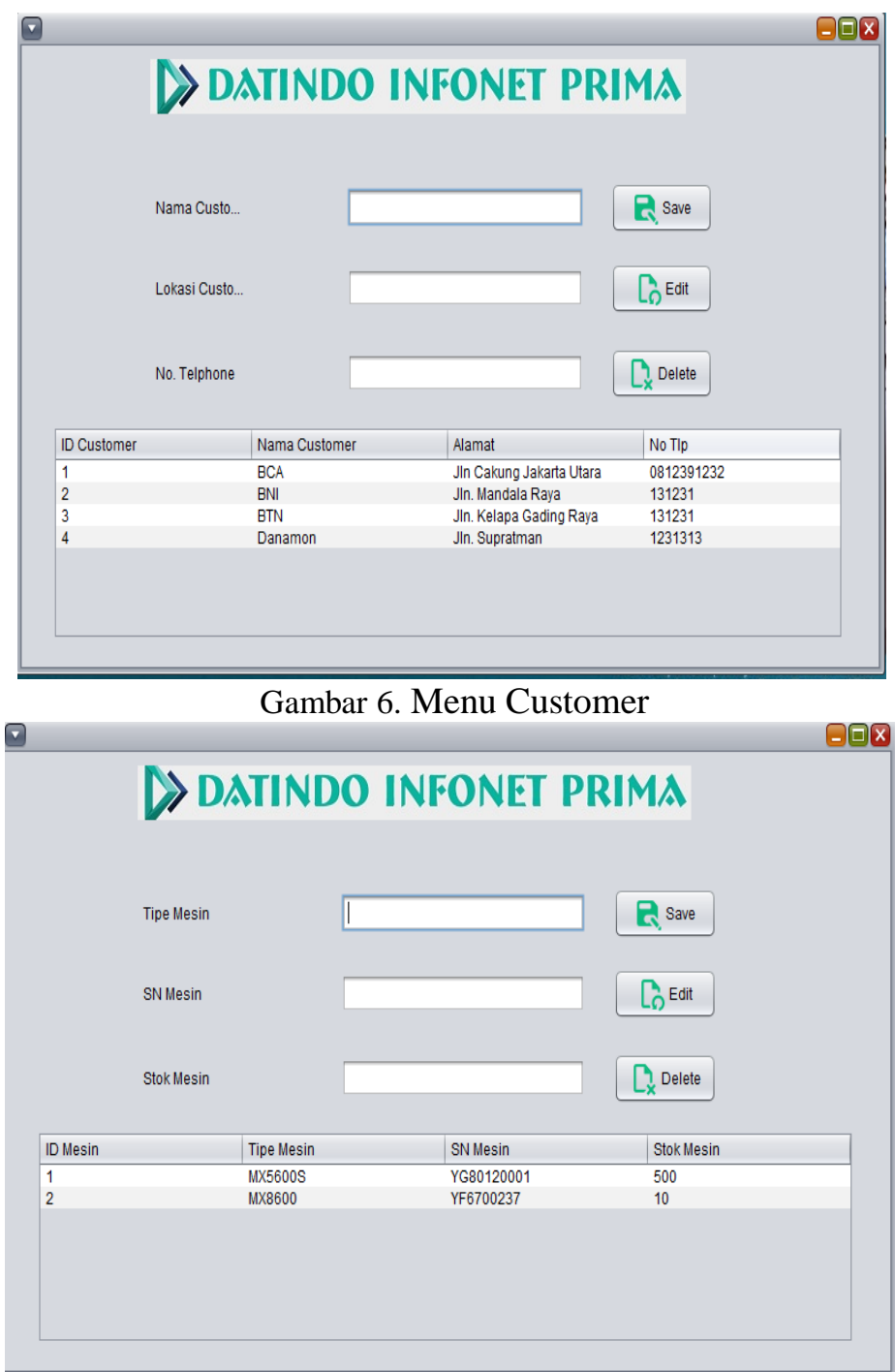

Gambar 7. Menu Barang 


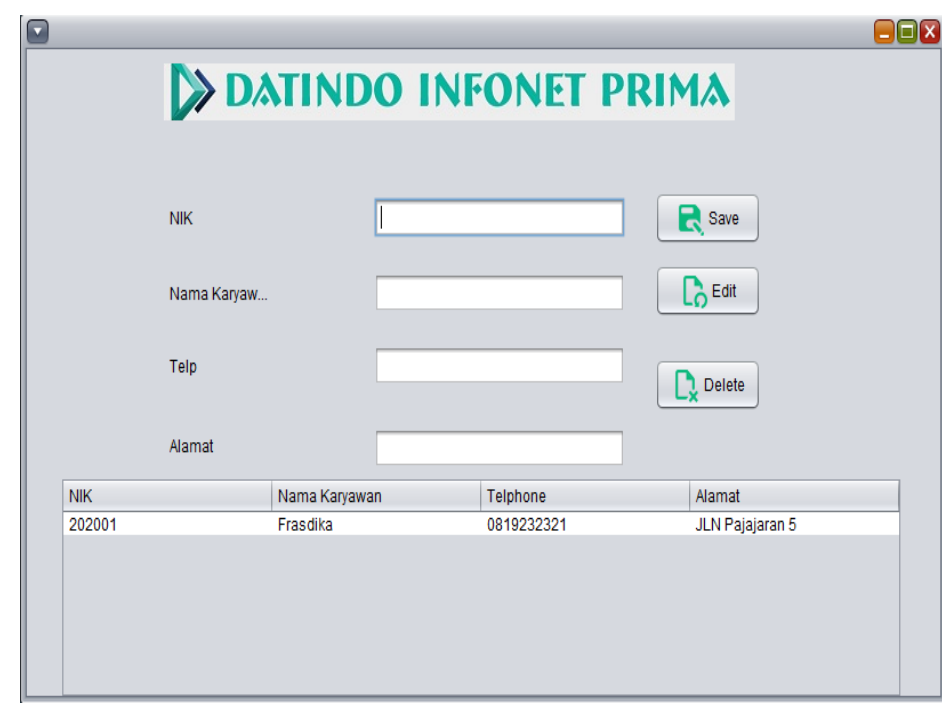

Gambar 8. Menu Karyawan

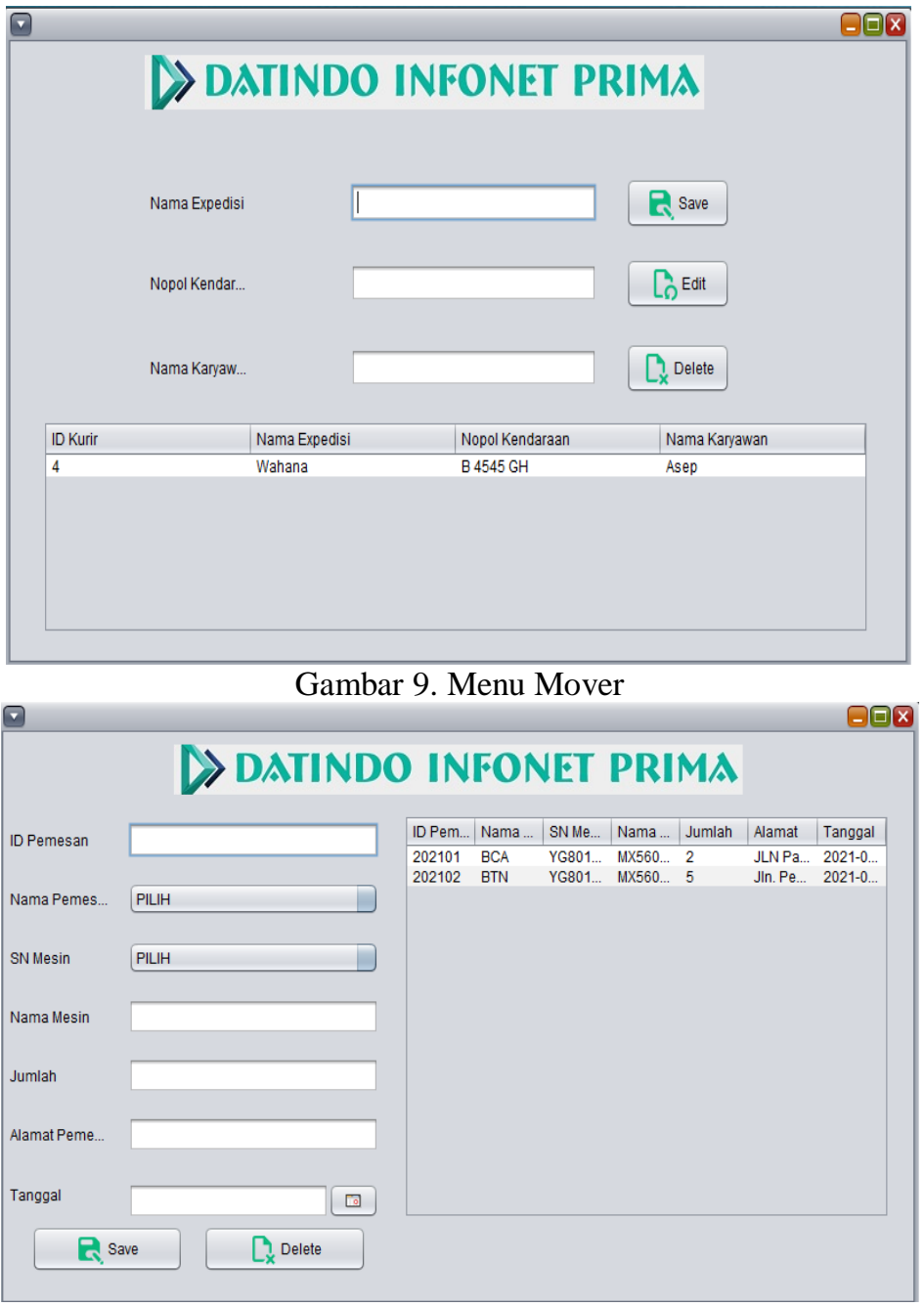

Gambar 10. Menu Pemesanan 


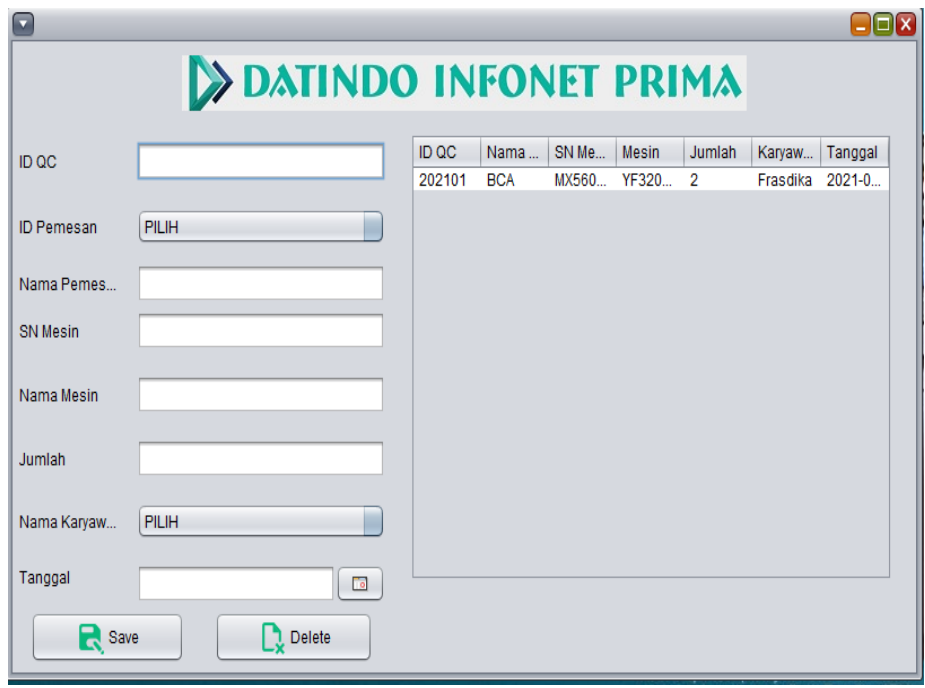

Gambar 11. Menu Quality Control

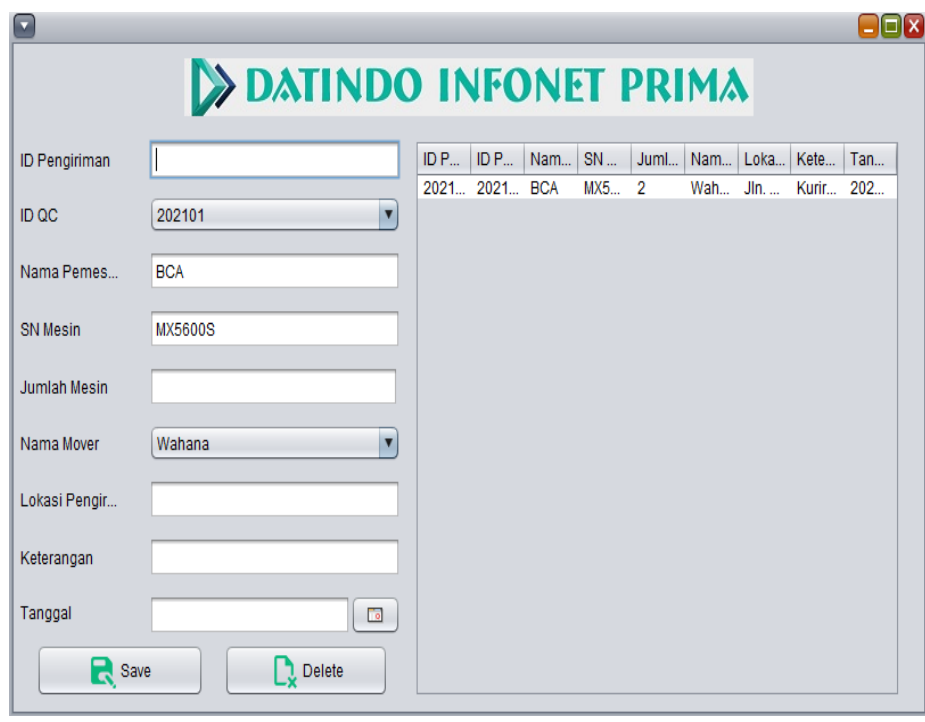

Gambar 12. Menu Pengiriman

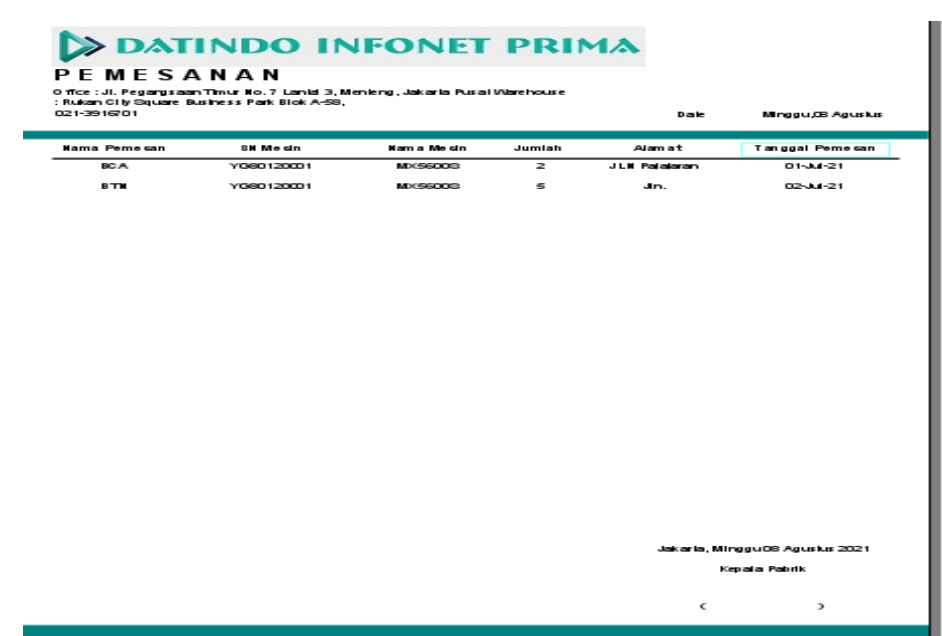

Gambar 13. Laporan Pemesanan 


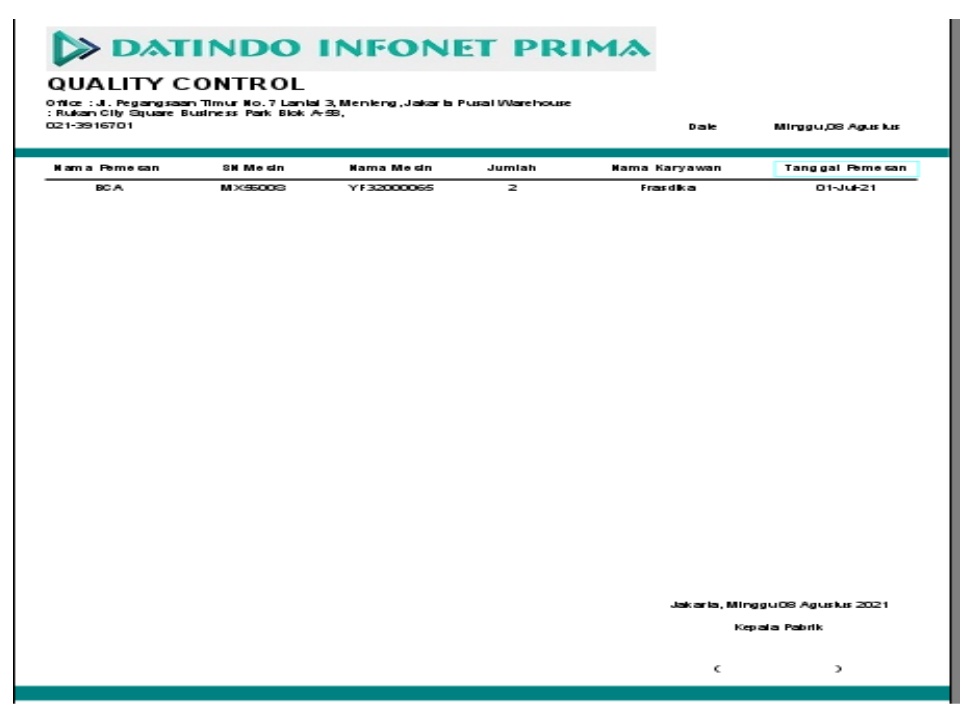

Gambar 14.Laporan Quality Control
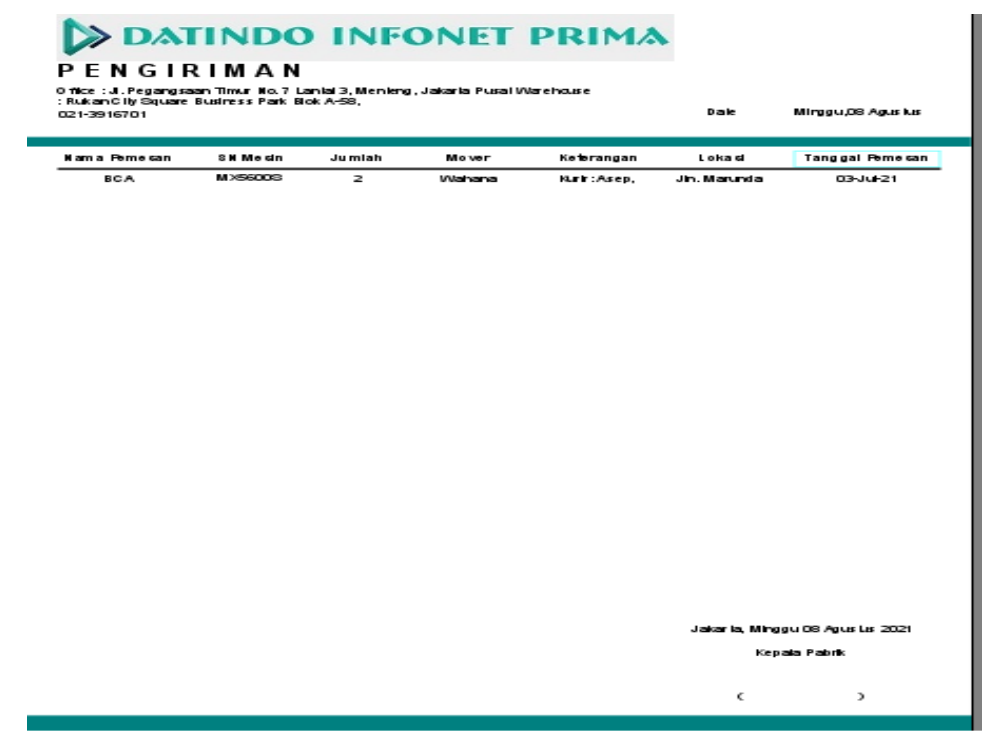

Gambar 15. Laporan Pengiriman

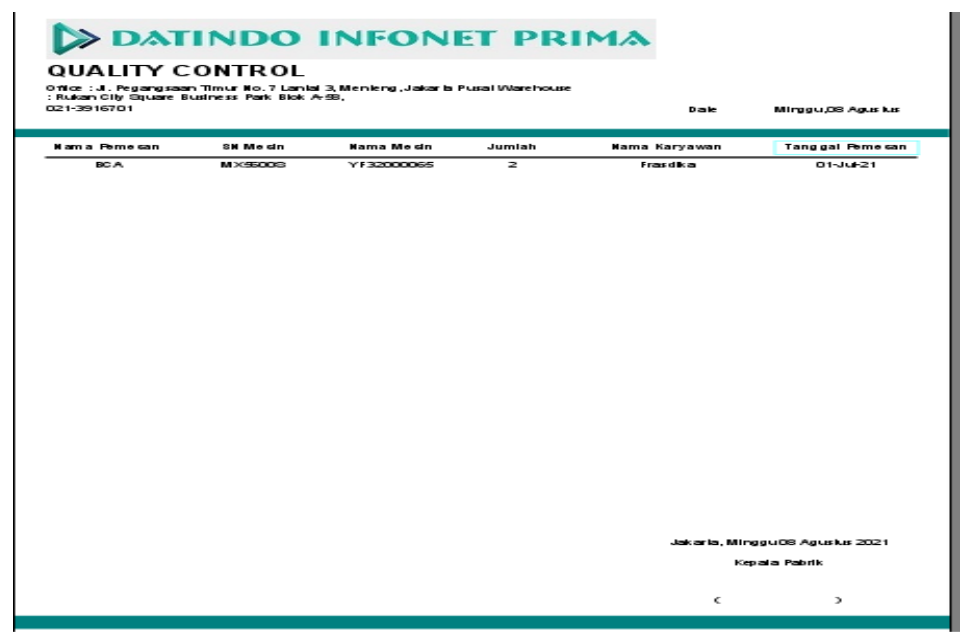

Gambar 16. Laporan Barang 


\section{Kesimpulan}

Beberapa kesimpulan yang diperoleh dari penelitian mengenai pembuatan sistem manajemen gudang pada PT. Datindo Infonet Prima Bekasi, antara lain:

1. Sistem manajemen gudang pada PT. Datindo Infonet Prima Bekasi dapat mempermudah user dalam menangani masalah pengelolaan data manajemen gudang yang sebelumnya telah berjalan di PT. Datindo Infonet Prima Bekasi.

2. Proses penyampaian informasi pengelolaan manajemen gudang pada PT. Datindo Infonet Prima Bekasi terhadap pimpinan perusahaan menjadi lebih tepat dan efisien.

3. Sistem manajemen gudang pada PT. Datindo Infonet Prima Bekasi bisa memberikan suatu nilai tambah bagi pengelola dalam mengelola data manajemen gudang.

\section{Daftar Pustaka}

[1] Anhar, S. T. (2010). Panduan Menguasai PHP \& MySQL secara Otodidak. Jakarta: Mediakita.Bachtiar, D. I., Atmoko, A. D., \& Priyanti, T. S. (2014). Implementasi sistem informasi akuntansi bagi usaha kecil dan menengah dalam meningkatkan akuntabilitas laporan keuangan. Jurnal Ekonomi dan Teknik Informatika, 2(1), hlm. 59-67.

[2] Bungin, B. (2015). Metodologi Penelitian Kuantitatif: Komunikasi, Ekonomi, dan Kebijakan Publik serta Ilmu-ilmu Sosial Lainnya. Jakarta: Kencana Prenada.

[3] Dhika, H., Isnain, N., \& Tofan, M. (2019). Manajemen villa menggunakan java netbeans dan mysql. IKRA-ITH: Jurnal Komputer dan Informatika, 3(2), hlm. 104-110. (Online), (https://journals.upiyai.ac.id/index.php/ikraith-informatika/article/view/324).

[4] Fahrizal, I., Hidayatullah, S. \& Marhaeni. (2016). Sistem informasi manajemen pergudangan sparepart berbasis sms gateway. Jurnal Rekayasa Informasi, 5(2), 34-42.

[5] Gelinas, U. J., Dull, R. B., \& Wheeler, P. (2011). Accounting Information Systems. Cengage Learning.

[6] Hakim, Z., Setiawan, S., \& Yanatris, Y. A. (2017). Perancangan sistem informasi penempatan barang jadi pada departemen gudang finish goods. Jurnal Sisfotek Global, 7(1), hlm. 13-20.

[7] Latif, F., \& Pratama, A. W. (2015). Perancangan sistem informasi manajemen arsip elektronik (e-arsip) berbasis microsoft access pada pt. hi-test. Jurnal Akuntansi, Ekonomi dan Manajemen Bisnis, 3(1), hlm. 21-31. (Online), (https://jurnal.polibatam.ac.id/index.php/JAEMB/article/download/180/168).

[8] Romney, M. B., \& Steinbart, P. J. (2015). Sistem Informasi Akuntansi. Jakarta: Salemba Empat.

[9] Setiawan, I. \& Romli, I. (2018). Sistem informasi pergudangan pada cv. cokro dengan model pengembangan sistem waterfall. SIGMA - Jurnal teknologi Pelita Bangsa, 9(1), hlm. 79-87.

[10] Sidh, R. (2013). Peranan brainware dalam sistem informasi manajemen. Jurnal Computech \& Bisnis, 7(1), hlm. 19-29.

[11] Silaen, S. (2018). Metodologi Penelitian Sosial untuk Penulisan Skripsi. Bandung: In Media.

[12] Sutabri, T. (2012). Analisa Sistem Informasi. Yogyakarta : Andi.

[13] _ (2016). Sistem Informasi Manajemen. Yogyakarta: Andi.

[14] Sutarman, B. (2012). Pengantar Teknologi Informasi. Jakarta: Bumi Aksara.

[15] M. Saputra, M. A. W. Andrian, and R. Hikmah, "Sistem Informasi Administrasi SDIT Mauritaniyyah," J. Nas. Komputasi dan Teknol. Inf., vol. 4, no. 2, pp. 131-137, 2021. 